\title{
A perspective on spaceflight associated neuro-ocular syndrome causation secondary to elevated venous sinus pressure
}

\author{
Grant Alexander Bateman (iD ${ }^{1,2 凶}$ and Alexander Robert Bateman ${ }^{3}$
}

\begin{abstract}
Spaceflight associated neuro-ocular syndrome (SANS) alters the vision of astronauts during long-duration spaceflights. There is controversy regarding SANS being similar to patients with idiopathic intracranial hypertension (IIH). IIH has been shown to be due to an elevation in venous sinus pressure. The literature suggests an increase in jugular vein pressure secondary to a headward shift of fluid occurs in SANS but this may not be enough to significantly alter the intracranial pressure (ICP). The literature regarding cardiac output and cerebral blood flow (CBF) in long-duration spaceflight is contradictory, however, more recent data suggests increased flow. Recent modelling has shown that an increase in CBF can significantly increase sinus pressure. The purpose of the present paper is to review the SANS vascular dynamics literature and through mathematical modelling suggest the possible underlying cause of SANS as an elevation in venous sinus pressure, secondary to the redistribution of fluids towards the head, together with a significant increase in pressure drop across the venous system related to the CBF.
\end{abstract}

npj Microgravity (2022)8:3; https://doi.org/10.1038/s41526-022-00188-6

\section{INTRODUCTION}

Spaceflight associated neuro-ocular syndrome (SANS) refers to the pathological effects of long-term microgravity on the eyes and orbital physiology of astronauts. The clinical manifestations of SANS include unilateral and bilateral optic disc oedema, globe flattening, choroidal and retinal folds, hyperopic refractive error shifts, and focal areas of ischaemic retina ${ }^{1}$. Although $15 \%$ of astronauts have clinically significant optic disc oedema, subclinical oedema has been detected in many astronauts returning from long-duration flights ${ }^{1}$.

It has been suggested the findings in SANS may be similar to terrestrial idiopathic intracranial hypertension $(\mathrm{IIH})^{1}$, however, others disagree ${ }^{2}$. IIH is characterised by an increased intracranial pressure (ICP) in the absence of parenchymal brain lesions, vascular malformations, hydrocephalus or central nervous system infection $^{3}$. To diagnose $\mathrm{IH}$, a cerebrospinal fluid (CSF) pressure above $25 \mathrm{~cm} \mathrm{H}_{2} \mathrm{O}(18.4 \mathrm{mmHg})$ is required according to the published guidelines ${ }^{4}$. A patient is suggested of having $\mathrm{IIH}$ if they have 3 out of 4 additional imaging criteria i.e. compression of the pituitary, flattening of the posterior globe, distention of the optic nerve sheath diameter (ONSD) or transverse venous sinus stenosis ${ }^{4}$. In long flight astronauts, globe flattening was seen in $26 \%$, optic nerve protrusion (optic disc oedema) in 15\% and pituitary flattening in $11 \%{ }^{5}$. Seven astronauts with globe flattening had a mean ONSD of $7.2 \mathrm{~mm}$ compared to 20 without globe flattening who had a mean ONSD of $5.8 \mathrm{~mm}(p=0.01)^{5}$. Although it should be acknowledged there was no pre-flight control data, the ONSD findings in the seven with orbital flattening are above the level associated with $\mathrm{IH}^{5}$. Thus, three of the imaging criteria for $\mathrm{IIH}$ are found in long flight veterans. Three of the astronauts underwent post-flight lumbar puncture showing pressures of 23,28 and $29 \mathrm{~cm} \mathrm{H}_{2} \mathrm{O}^{5}$ (inflight data is not available), with 2 of these pressures being in the diagnostic range for $\mathrm{IH}^{4}$. A counterpoint paper suggests there is no evidence of ONSD enlargement secondary to spaceflight ${ }^{6}$ but the study was underpowered and had only one individual who developed SANS. This individual had an increase in ONSD in the range suggestive of IIH.

It can be seen that by utilising the revised IIH criteria, there are some astronauts who would fulfil the criteria for IIH. The purpose of this perspective is to review the literature in SANS with respect to the blood and CSF dynamics. Following this, computational fluid dynamics modelling will be utilised to suggest the possible causes of SANS in astronauts undergoing long-duration space flight and to suggest a vascular aetiology for SANS which is similar to $\mathrm{IIH}$.

\section{DISCUSSION}

There are similarities between SANS and $\mathrm{IH}$, however, there are also differences. Terrestrial symptoms of IIH include headache and pulsatile tinnitus, but astronauts with SANS do not complain of these symptoms ${ }^{7}$. IIH presents more often as bilateral eye changes, predominately in women, but SANS has a higher asymmetric or unilateral presentation and is more common in men ${ }^{1}$. Transient visual obscurations or diplopia secondary to a non-localising sixth nerve palsy have never been reported in astronauts with SANS, unlike $\mathrm{IIH}^{1}$. Despite these differences, there remain enough similarities to suggest some commonality may exist in the pathophysiology of both.

The main criteria for IIH is an elevation in the ICP which is modelled using Davson's equation

$$
\mathrm{ICP}=\mathrm{FR}_{\mathrm{CSF}} \times R_{\text {out }}+\mathrm{SSS}_{\mathrm{p}}
$$

where $\mathrm{FR}_{\mathrm{CSF}}$ is the CSF formation rate, $R_{\text {out }}$ is the CSF outflow resistance and $\mathrm{SSS}_{\mathrm{p}}$ is the superior sagittal sinus pressure. The sagittal sinus pressure is analogous to Ohm's law, i.e. pressure is the product of the outflow resistance and blood flow through the outflow plus the jugular bulb pressure ${ }^{8}$. So Eq. (1) can be expanded to

$\mathrm{ICP}=\mathrm{FR}_{\mathrm{CSF}} \times R_{\text {out }}+\mathrm{TCBF} \times R_{\text {ven }}+\mathrm{JBP}$

\footnotetext{
Department of Medical Imaging, John Hunter Hospital, Newcastle, NSW, Australia. ${ }^{2}$ Newcastle University Faculty of Health, Callaghan Campus, Newcastle, NSW, Australia.

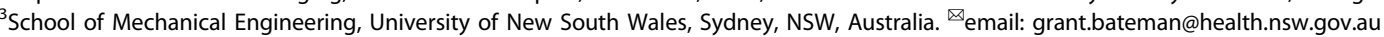


where TCBF is the total blood flow leaving the capillaries to enter the venous system, $R_{\text {ven }}$ is the venous outflow resistance from the sagittal sinus to the jugular bulbs and JBP is the jugular bulb pressure. The CSF formation rate is normal in IIH and decreases as the ICP increases 9 . The pressure gradient between the CSF and sagittal sinus was found to low-normal at $2.34 \mathrm{mmHg}$ in one paper in $\mathrm{IH}^{10}$ and $2.7 \mathrm{mmHg}$ in another ${ }^{11}$. Rearranging Eq. (1) by subtraction, the ICP to sagittal sinus pressure gradient is equal to the $F R_{c s f} \times R_{\text {out }}$, and if this term is normal, then the elevation in ICP in IIH can only be due to elevated venous pressure. This discussion tends to validate the original assertion made by Karahalios et al. i.e. "an elevated venous pressure is the universal mechanism underlying $\mathrm{IIH}^{\prime \prime 2}$. Is a venous pressure elevation also the universal cause of SANS?

The normal ICP is $15.6 \mathrm{~cm} \mathrm{H} \mathrm{H}_{2} \mathrm{O}$ or $11.5 \mathrm{mmHg}$ in the lateral decubitus position in adults between 20 and 49 years ${ }^{13}$. The criteria for IIH is an ICP of $18.4 \mathrm{mmHg}$ (or $25 \mathrm{~cm} \mathrm{H}_{2} \mathrm{O}$ ) ) $^{4}$ Thus a prolonged increase in venous sinus pressure of approximately $7 \mathrm{mmHg}$ would be required if SANS were analogous to $\mathrm{IH}$. As previously described, the venous sinus pressure depends on the combination of the jugular bulb pressure, venous outflow resistance and the total blood flow passing through the venous system. In adults with $\mathrm{IIH}, 71 \%$ are obese ${ }^{14}$. Obesity raises the jugular bulb pressure by up to $20 \mathrm{mmHg}^{15}$. Up to $90 \%$ of adults with IIH have been found to have outflow stenosis mostly sited at the middle of the transverse sinus, raising the venous resistance and therefore the venous pressure ${ }^{16}$. Sixty-six per cent of the increase in ICP in IIH is due to venous stenosis and 34\% is due to obesity $^{17}$. Astronauts are not obese ${ }^{1}$. A recent paper comparing the venous sinus volumes, both before and after spaceflight, showed a significant increase in the size of the superior sagittal, transverse and sigmoid sinuses (not stenosis) in those who developed SANS, compared to those who did not ${ }^{18}$. In another paper, in three long-duration astronauts with borderline or elevated CSF opening pressures, the MRV images were reported as normal with no evidence of stenosis or thrombosis ${ }^{19}$.

Therefore, if the physiology of SANS is similar to $\mathrm{IH}$, there must be other factors elevating the venous sinus pressure.

\section{Current hypotheses regarding SANS aetiology}

The main hypothesis regarding the cause of SANS centres on a rise in ICP due to the cephalad fluid shifts occurring during longduration spaceflight ${ }^{1}$. Similar to obesity, this would have the effect of directly raising the venous sinus pressure. A second hypothesis suggests that CSF accumulates in the optic nerve sheath due to a one-way valve mechanism ${ }^{20}$. This hypothesis would explain the eye findings but not the elevated ICP or pituitary compression found in some astronauts. A third hypothesis suggests that SANS is due to upward shift of the brain putting tension on the optic nerve sheath ${ }^{21}$. This hypothesis is not necessarily mutually exclusive of hypothesis 1 but of itself does not explain the elevation in ICP.

\section{Cephalad fluid shift hypothesis}

Ideally, all hypotheses would be tested on astronauts whilst in space, during a long-duration flight. However, the numbers of subjects available are limited, an astronaut's time in space is precious and the technique used must be achievable in space and must match the expertise of the subjects. For example, performing magnetic resonance imaging (MRI) or lumbar punctures on board the International Space Station is not feasible. Thus, ground-based space analogues are utilised. Analogues such as supine bed rest, head-down tilt bed rest (HDTBR), wet and dry immersion, lowerextremity limb suspension and parabolic flight have been tried ${ }^{22}$.

One space-based study used ultrasound-guided jugular vein compression. The terrestrial jugular venous pressure varies between the two-thirds of the day one spends upright and the one-third supine. If one weighted the pressures found $(66 \%$ of the upright figure plus $33 \%$ of the supine) then the 24-h weighted average jugular venous pressure was found to be $9.2 \mathrm{mmHg}$ when on the ground and increased by $6.6 \mathrm{mmHg}$ at day 150 during long term weightlessness ${ }^{23}$. Note that this is very close to the $7 \mathrm{mmHg}$ increase in pressure required to trigger terrestrial IIH. Head-down tilt experiments, similar to the jugular vein compression study, indicate that a headward redistribution of fluid brings about a dilatation of the jugular veins with some evidence of increased $\mathrm{ICP}^{24}$. Strict head-down tilt experiments can cause retinal thickening and chorioretinal folds but no changes in refractive error or perimetry developed ${ }^{25}$. This suggests the headward shift is able to produce a syndrome similar to mild SANS.

\section{Cardiac output during long-term spaceflight and HDTBR}

During spaceflight, the cardiac output (CO) appears to depend on which technique is used. Two studies using ultrasound echocardiography observed a decrease in stroke volume and CO during flight $^{26,27}$. Hughson et al. used the continuous finger blood pressure contour technique and found no changes in stroke volume $^{28}$. However, Norsk et al. found significant increases in stroke volume and CO of as much as 35 and $41 \%$, respectively, between 3 and 6 months of flight on the ISS ${ }^{29}$. A foreign gas rebreathing technique was used ${ }^{29}$. Hughson et al. later measured $\mathrm{CO}$ and stroke volume by the same method as Norsk et al. and found similar increases ${ }^{30}$. They concluded that their previously unchanged stroke volume and $\mathrm{CO}$ estimations had been incorrect ${ }^{30}$. The increase in CO of $41-56 \%$ after months ${ }^{29,30}$ is higher than the increase measured by the same technique i.e.18-26\% reported from shorter week long-Space Shuttle missions ${ }^{31-33}$. Thus, long durations in space produce higher stroke volumes and COs than a short duration. Norsk comments, both foreign gas rebreathing and ultrasound techniques have been validated thoroughly and multiple times against invasive more direct, gold standard techniques. The foreign gas rebreathing method is observer-independent and obtains data over a longer time period (20s) than the ultrasound Doppler (three cardiac cycles) and that the breathing frequency and depth are controlled and kept constant during the measurements. Thus, he suggests the gas technique is probably correct ${ }^{34}$. The cerebral blood flow (CBF) at rest is $15-20 \%$ of the total $\mathrm{CO}^{35}$ and the renal blood flow is $20 \%$ of $\mathrm{CO}^{36}$, In a low powered study of only 5 individuals, the renal plasma flows increased by $17 \%$ at 1 week in orbit but this was not significantly different to preflight values ${ }^{37}$. If a larger cohort had found this difference to be significant then this would be similar to the $18-26 \%$ increase in CO found by Norsk ${ }^{31-33}$. The $\mathrm{CO}$ must all pass through a capillary bed to return to the heart. If the $\mathrm{CO}$ is increased by $41 \%$ then the renal and CBFs cannot be normal.

\section{CBF in space flight and HDTBR}

Similar to the findings in $\mathrm{CO}$, the CBF findings seem to depend on the technique being used. A 5-day flight of a Rhesus monkey on the Cosmos 1514 biosatellite fitted with a carotid flow sensor showed a sustained $8 \mathrm{~cm} / \mathrm{s}$ increase in blood velocity ${ }^{38}$. Impedance rheoencephalography has shown increased CBF both during and immediately after flight ${ }^{39-43}$. Transcranial Doppler (TCD) showed an increase in straight sinus velocity in $9 / 13$ astronauts, with flow velocities ranging from $30-47 \mathrm{~cm} / \mathrm{sec}$ and the normal range being $14-28 \mathrm{~cm} / \mathrm{sec}^{44}$.

The transcranial Doppler of the middle cerebral arterial literature in spaceflight is contradictory. Some studies suggest an increase in cerebral blood velocity ${ }^{45-48}$, some unchanged ${ }^{49,50}$ and some decreased flow ${ }^{51,52}$. The divergence between the previously described measures of CBF and the transcranial Doppler velocity is striking. The original validation studies for TCD showed the correlation between the arterial velocity and the 
gold standard for CBF (xenon $133 \mathrm{CT}$ ) was weak at $r=0.42^{53}$. This is because the CBF depends on both the velocity of the blood and the cross-sectional area of the vessel. If the middle cerebral artery is constricted, the CBF will fall but the velocity will increase and in reverse, the velocity will drop but the flow increases when the diameter increases ${ }^{54}$. The middle cerebral artery lumen can increase in size by $45 \%$ by altering carbon dioxide $\left(\mathrm{CO}_{2}\right)$ levels from low-normal to high-normal ${ }^{55}$. Theoretically, if the CBF increased purely due to an increase in diameter, then the TCD could underestimate the effect by $45 \%$. Indeed, Coverdale et al. found a change in middle cerebral artery cross-sectional area during acute hypercapnia resulted in a CBF underestimation by TCD of $18 \%{ }^{56}$.

A recent study has shown a significant increase in the middle cerebral vein velocity on day 150 of spaceflight and ascribed this to a reduction in the vein diameter with a resulting normal venous flow volume ${ }^{57}$. However, the $84 \%$ increase in velocity found would require a $46 \%$ reduction in vein diameter to give a normal blood flow volume ${ }^{57}$. This would require the ICP to approach cerebral perfusion pressure ${ }^{58}$. This is because as the ICP increases the collapse of veins begins close to their outflow with the more proximal sections (where TCD measures velocity) being increased in size ${ }^{59}$. Only once the pressure reaches perfusion pressure will the whole vein collapse. No one suggests ICP approaches perfusion pressure in space as this would be lethal. Roberts et al. found some elevation of the brain and crowding of the sulci over the vertex and suggested this could lead to venous narrowing or arachnoid granulation obstruction. However, static pressures are equally distributed throughout a water bath and the reduction in the sulci was mild and unlikely to be water tight ${ }^{58}$. If the TCD vein diameter is normal then an increase in velocity must indicate an increase in blood flow volume.

Similar to the TCD findings, HDTBR studies tend to show a reduced CBF. This is perhaps not surprising as HDTBR also produces a reduction in cardiac stroke volume and $\mathrm{CO}^{60}$. There appears to be a distinct physiological difference between spaceflight and HDTBR. Thirteen days of space flight in a mouse model led to both a decrease in myogenic vasoconstrictor tone and an increase in arterial distention, leading to a $20 \%$ increase in resting cross-sectional area $^{61}$. This would be consistent with lower vascular resistance and higher CBF during space flight ${ }^{61}$. This compared to control head-down tilt mice where there was no effect on vasoconstriction, passive pressure-diameter response or maximal diameter ${ }^{61}$. Using an MRI arterial spin labelling (ASL) technique, 30 days of head-down tilt plus increased $\mathrm{CO}_{2}$, demonstrated the expected decrease in $\mathrm{CBF}^{62}$. However, the five participants who developed optic disc oedema had higher CBF (approaching the baseline levels) compared with the non-oedema group ${ }^{62}$. This suggests that variations in vasoreactivity and autoregulatory responses to $\mathrm{CO}_{2}$ may play a role in SANS development ${ }^{62}$. Acute hypercapnia increases the $\mathrm{CBF}$ but the effect is short-lived being corrected within a few hours ${ }^{63}$. However, there is a delayed, more long-lasting vasodilatation occurring with chronic $\mathrm{CO}_{2}$ elevation which appears to be genetically mediated ${ }^{63}$. In chronic obstructive pulmonary disease, patients retain $\mathrm{CO}_{2}$. A reduction in the $\mathrm{CO}_{2}$ by non-invasive positive pressure ventilation reduced the middle cerebral artery TCD velocity by $23 \%$ without affecting the oxygen levels ${ }^{64}$. It should be noted TCD may have underestimated this effect. In a series of patients undergoing ASL MRI, those found to have an elevated $\mathrm{CO}_{2}$ had a grey matter $\mathrm{CBF}$ double the patients with $\mathrm{CO}_{2}$ in the normal range ${ }^{65}$. The effect was not statistically different between acute and chronic hypercapnia ${ }^{65}$. Overall, there was a $6.7 \%$ increase in CBF per 1-mmHg rise in partial pressure of $\mathrm{CO}_{2}{ }^{65}$. Interestingly, women tended to be more resistant to the effect of $\mathrm{CO}_{2}$ than men ${ }^{65}$ which may point to a reason why men are more prone to develop SANS than women.
Thus, an increase in CO and CBF in long-term space flight may be related to $\mathrm{CO}_{2}$ in long-duration spaceflight. Technical constraints maintain carbon dioxide levels at nearly 10 times earth normal levels ${ }^{1}$. Air convection is also significantly reduced in microgravity and pockets of $\mathrm{CO}_{2}$ may develop around the nose and mouth of astronauts. At an ambient partial pressure of $\mathrm{CO}_{2}$ of $3.8 \mathrm{mmHg}$ during flight, the expired $\mathrm{CO}_{2}$ of a cohort of astronauts was $6.1 \mathrm{mmHg}$ higher than pre-flight levels ${ }^{66}$. There is a $6-6.7 \%$ increase in $\mathrm{CBF}$ for each $1-\mathrm{mmHg}$ rise in partial pressure of $\mathrm{CO}_{2}{ }^{65,67}$. This indicates the CBF could be increased by the $41 \%$ increase in $\mathrm{CO}$ noted by Norsk et al. ${ }^{29}$. Forty-five per cent of children with $\mathrm{IIH}$ have cerebral hyperaemia ${ }^{17}$. A study in patients with $\mathrm{IIH}$ showed a $56 \%$ increase in $\mathrm{CO}_{2}$ led to a $166 \%$ increase in superior sagittal sinus pressure ${ }^{68}$ indicating the effect of $\mathrm{CO}_{2}$ on sinus pressure is non-linear. In a modelling study, the increase in blood returning through the venous system significantly increased the pressure drop from the sagittal sinus to the jugular bulbs because the pressure response to CBF of the venous system was quadratic in nature ${ }^{69}$. The cause of the greater than the linear response of the venous system to blood flow is due to the development of rotational or vortex flow induced by the unusual geometry. Could an increased blood flow in long-term space flight increase the venous pressure is SANS? The normal arterial inflow for a group of average age 43 years is $792 \mathrm{mls} / \mathrm{min}^{70}$. A $40 \%$ increase in arterial inflow secondary to the elevated $\mathrm{CO}_{2}$ would lead to a mean arterial inflow of $1110 \mathrm{mls} / \mathrm{min}$. If we were to recruit the 5 normal individuals who had their normal venous outflow modelled with computational fluid dynamics (CFD) in our original paper ${ }^{69}$, and place them in orbit for 6 months, then we can see from Fig. 1 that there would be a variable increase in the venous pressure. The normal pressure drop across the cerebral venous system is $2.5 \mathrm{mmHg}$ in middle age ${ }^{17}$. IIH needs an increase in venous pressure of $7 \mathrm{mmHg}$ to develop. We can see in Fig. 1 that under hyperaemic conditions patient 4 would have no significant increase in pressure drop across the venous system compared to normal and presumably not be at high risk for $\mathrm{IIH}$. Patients 5 and 1 would have pressure drops of 1.7 and $1.8 \mathrm{mmHg}$, respectively, above the normal figure, giving an increase in sinus pressure overall (once the $6.6 \mathrm{mmHg}$ increase in jugular vein

\section{Venous pressure response verses blood flow for five normal individuals}

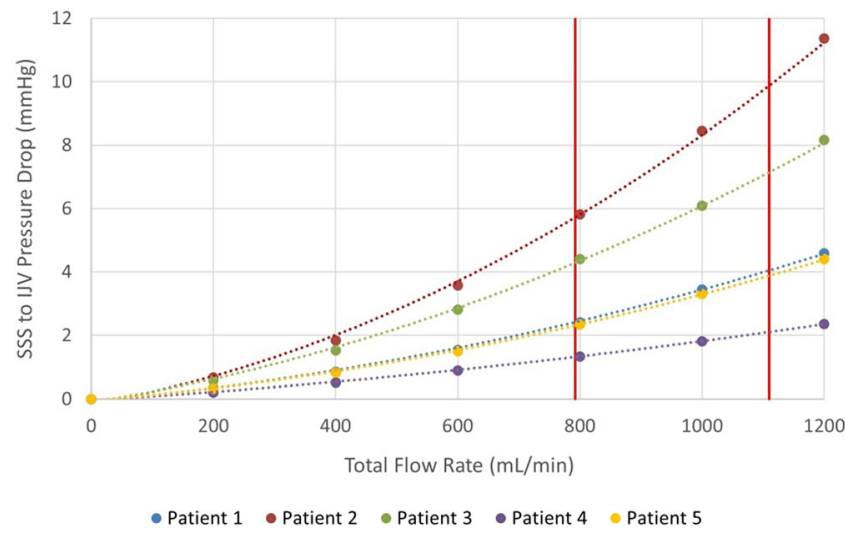

Fig. 1 Venous pressure vs. blood flow. A graph of the venous pressure response vs. blood flow for the five patients modelled in reference ${ }^{69}$. The two vertical lines represent the normal flow rate at middle age on the left $(792 \mathrm{mls} / \mathrm{min})$ and a $40 \%$ increase in flow on the right $(1110 \mathrm{mls} / \mathrm{min})$. Note the pressure drop across the venous system is close to the normal figure of $2.5 \mathrm{mmHg}$ at a normal flow rate for 3 of the 5 patients but elevated in 2. At a flow rate of $1110 \mathrm{mls} / \mathrm{min}$ there is a wide variation in response meaning there is a variable risk for the development of SANS if this condition is analogous to IIH. IVJ internal jugular vein, SSS superior sagittal sinus. 
pressure from the headward fluid shift is added) of 8.3 and $8.4 \mathrm{mmHg}$ and be at moderate risk of $\mathrm{IIH}$ and perhaps SANS. Patients 3 and 2 would have sinus pressure drops of 4.5 and $7.3 \mathrm{mmHg}$ above normal, giving total sinus pressure increases of 11.1 and $13.9 \mathrm{mmHg}$ and presumably be at a high risk of developing IIH and possibly SANS. Fifteen per cent of longduration space flight astronauts have SANS and $20 \%$ have choroidal folds ${ }^{1}$, perhaps correlating with the $20 \%$ of our venous blood flow models which have suggested a large increase in pressure with increased CBF. The fivefold variation in the pressure response to the same increase in blood flow noted suggests that there is a wide variation in response to cerebral hyperaemia in normal individuals. Therefore, there may be some utility in performing CFD modelling studies on the venous outflow of prospective long-duration astronauts to try and stratify the risk of developing SANS.

\section{METHODS}

Initially, a literature search was undertaken in PUBMED looking for all research papers written in the English language with the search criteria "spaceflight associated neuro-ocular syndrome" or "vision impairment intracranial pressure". Ninety-eight responses were obtained. Papers were chosen for review on the basis of discussing the CSF or blood flow dynamics. After the review, mathematical estimation of venous pressure in long term space flight was undertaken to utilise the computational fluid dynamic modelling undertaken by one of the authors (A.B.). The modelling data consists of 5 computational fluid dynamic models of the cerebral venous outflow from the sagittal sinus to the jugular veins obtained from the $C T$ venogram images of patients who did not have evidence of cerebral disease, please see the original modelling study for further details ${ }^{69}$. Some of this data has been previously published ${ }^{69}$. Informed consent was obtained from all five patients who had their CT venogram data modelled to provide Fig. 1. The study original modelling study was approved by the Hunter New England Area Health Ethics Committee, therefore, the original study has been performed in accordance with the ethical standards laid down in the 1964 Declaration of Helsinki. The authorisation number HREG/10/NHE/132 was issued.

\section{Reporting summary}

Further information on research design is available in the Nature Research Reporting Summary linked to this article.

\section{DATA AVAILABILITY}

The data that support the findings of this study are available from the corresponding author upon reasonable request.

Received: 10 June 2021; Accepted: 21 January 2022;

Published online: 15 February 2022

\section{REFERENCES}

1. Lee, A. G. et al. Spaceflight associated neuro-ocular syndrome (SANS) and the neuro-ophthalmologic effects of microgravity: a review and an update. NPJ Microgravity 6, 7 (2020).

2. Kesserwani, H. Space flight-associated neuroocular syndrome, idiopathic intracranial hypertension, and pseudotumor cerebri: phenotypic descriptions, pathogenesis, and hydrodynamics. Cureus 13, e14103 (2021).

3. Cleves-Bayon, C. Idiopathic intracranial hypertension in children and adolescents: an update. Headache 58, 485-493 (2018).

4. Friedman, D. I., Liu, G. T. \& Digre, K. B. Revised diagnostic criteria for the pseudotumor cerebri syndrome in adults and children. Neurology 81, 1159-1165 (2013).

5. Kramer, L. A., Sargsyan, A. E., Hasan, K. M., Polk, J. D. \& Hamilton, D. R. Orbital and intracranial effects of microgravity: findings at 3-T MR imaging. Radiology 263, 819-827 (2012).
6. Rohr, J. J. et al. Quantitative magnetic resonance image assessment of the optic nerve and surrounding sheath after spaceflight. NPJ Microgravity 6, 30 (2020).

7. Ong, J., Lee, A. G. \& Moss, H. E. Head-down tilt bed rest studies as a terrestrial analog for spaceflight associated neuro-ocular syndrome. Front. Neurol. 12, 648958 (2021).

8. Bateman, G. Hyperemic hydrocephalus: a new form of childhood hydrocephalus analogous to hyperemic intracranial hypertension in adults. J. Neurosurg. Pediatr. 5, 20-26 (2010).

9. Guess, H. A., Charlton, J. D., Johnson, R. N. \& Mann, J. D. A nonlinear least-squares method for determining cerebrospinal fluid formation and absorption kinetics in pseudotumor cerebri. Comput. Biomed. Res. 18, 184-192 (1985).

10. Lalou, A. D. et al. Coupling of CSF and sagittal sinus pressure in adult patients with pseudotumour cerebri. Acta Neurochir. 162, 1001-1009 (2020).

11. Liu, K. C. et al. Venous sinus stenting for reduction of intracranial pressure in IIH: a prospective pilot study. J. Neurosurg. 127, 1126-1133 (2017).

12. Karahalios, D. G., Rekate, H. L., Khayata, M. H. \& Apostolides, P. J. Elevated intracranial venous pressure as a universal mechanism in pseudotumor cerebri of varying etiologies. Neurology 46, 198-202 (1996).

13. Fleischman, D. et al. Cerebrospinal fluid pressure decreases with older age. PLoS ONE 7, e52664 (2012).

14. Rowe, F. J. \& Sarkies, N. J. The relationship between obesity and idiopathic intracranial hypertension. Int. J. Obes. Relat. Metab. Disord. 23, 54-59 (1999).

15. Sugerman, H. J., DeMaria, E. J., Felton, W. L. 3rd, Nakatsuka, M. \& Sismanis, A. Increased intra-abdominal pressure and cardiac filling pressures in obesityassociated pseudotumor cerebri. Neurology 49, 507-511 (1997).

16. De Simone, R. et al. Dural sinus collapsibility, idiopathic intracranial hypertension, and the pathogenesis of chronic migraine. Neurol. Sci. 40, 59-70 (2019).

17. Bateman, G. A., Subramanian, G. M., Yap, S. L. \& Bateman, A. R. The incidence of obesity, venous sinus stenosis and cerebral hyperaemia in children referred for MRI to rule out idiopathic intracranial hypertension at a tertiary referral hospital: a 10 year review. Fluids Barriers CNS 17, 59 (2020).

18. Rosenberg, M. J. et al. Comparison of dural venous sinus volumes before and after flight in astronauts with and without spaceflight-associated neuro-ocular syndrome. JAMA Netw. Open 4, e2131465 (2021).

19. Stenger, M. B. et al. Evidence report: risk of spaceflight associated neuro-ocular syndrome (SANS). https://humanresearchroadmap.nasa.gov.au/evidence/reports/ SANS.pdf.2017 (2017).

20. Killer, H. E. et al. Cerebrospinal fluid dynamics between the intracranial and the subarachnoid space of the optic nerve. Is it always bidirectional? Brain 130, 514-520 (2007).

21. Shinojima, A., Kakeya, I. \& Tada, S. Association of space flight with problems of the brain and eyes. JAMA Ophthalmol. 136, 1075-1076 (2018).

22. Pandiarajan, M. \& Hargens, A. R. Ground-based analogs for human spaceflight. Front. Physiol. 11, 716 (2020).

23. Marshall-Goebel, K. et al. Assessment of jugular venous blood flow stasis and thrombosis during spaceflight. JAMA Netw. Open 2, e1915011 (2019).

24. Watkins, W., Hargens, A. R., Seidl, S., Clary, E. M. \& Macias, B. R. Lower-body negative pressure decreases noninvasively measured intracranial pressure and internal jugular vein cross-sectional area during head-down tilt. J. Appl Physiol. 123, 260-266 (2017).

25. Laurie, S. S. et al. Optic disc edema and chorioretinal folds develop during strict 6 degrees head-down tilt bed rest with or without artificial gravity. Physiol. Rep. 9, e14977 (2021).

26. Herault, S. et al. Cardiac, arterial and venous adaptation to weightlessness during 6-month MIR spaceflights with and without thigh cuffs (bracelets). Eur. J. Appl. Physiol. 81, 384-390 (2000).

27. Hamilton, D. R. et al. On-orbit prospective echocardiography on International Space Station crew. Echocardiography 28, 491-501 (2011).

28. Hughson, R. L. et al. Cardiovascular regulation during long-duration spaceflights to the International Space Station. J. Appl Physiol. 112, 719-727 (2012).

29. Norsk, P., Asmar, A., Damgaard, M. \& Christensen, N. J. Fluid shifts, vasodilatation and ambulatory blood pressure reduction during long duration spaceflight. $J$. Physiol. 593, 573-584 (2015).

30. Hughson, R. L., Peterson, S. D., Yee, N. J. \& Greaves, D. K. Cardiac output by pulse contour analysis does not match the increase measured by rebreathing during human spaceflight. J. Appl Physiol. 123, 1145-1149 (2017).

31. Prisk, G. K., Guy, H. J., Elliott, A. R., Deutschman, R. A. 3rd \& West, J. B. Pulmonary diffusing capacity, capillary blood volume, and cardiac output during sustained microgravity. J. Appl Physiol. 75, 15-26 (1993).

32. Shykoff, B. E. et al. Cardiovascular response to submaximal exercise in sustained microgravity. J. Appl Physiol. 81, 26-32 (1996).

33. Norsk, P. et al. Vasorelaxation in space. Hypertension 47, 69-73 (2006).

34. Norsk, P. Adaptation of the cardiovascular system to weightlessness: Surprises, paradoxes and implications for deep space missions. Acta Physiol. 228, e13434 (2020).

35. Kety, S. S. Circulation and metabolism of the human brain in health and disease. Am. J. Med. 8, 205-217 (1950). 
36. Botti, R. E., Razzak, M. A., Maclntyre, W. J. \& Pritchard, W. H. The relationship of renal blood flow to cardiac output in normal individuals as determined by concomitant radioisotopic measurements. Cardiovasc. Res. 2, 243-246 (1968).

37. Leach, C. S. et al. Regulation of body fluid compartments during short-term spaceflight. J. Appl. Physiol. 81, 105-116 (1996).

38. Sandler, $\mathrm{H}$. et al. Cardiovascular results from a rhesus monkey flown aboard the Cosmos 1514 spaceflight. Aviat. Space Environ. Med. 58, 529-536 (1987).

39. Moskalenko, Y. E., Weinstein, G. B. \& Semernja, V. N. Investigation of human cerebral circulation in spaceflight conditions. Aviat. Space Environ. Med. 46, 1023-1026 (1975).

40. Turchaninova, V. F., Egorov, A. D. \& Domracheva, M. V. Central and regional hemodynamics in long space flights. Kosm. Biol. Aviakosm Med. 23, 19-26 (1989).

41. Vasil'eva, T. D., larullin, K. \& Zhuǐko, V. I. Regional hemodynamic changes following space flights lasting up to 8 days. Kosm. Biol. Aviakosm Med. 16, 12-17 (1982).

42. Iarullin, K., Vasil'eva, T. D., Turchaninova, V. F., Sokolova, I. V. \& Vikharev, N. D. Compensatory-adaptive reactions of regional hemodynamics to weightlessness during a long space flight. Kosm Biol. Aviakosm Med. 18, 22-28 (1984).

43. Yegorov, A. D. et al. Studies of cardiovascular system in prolonged spaceflights aboard Salyut orbital stations. Izvestiya. Akad. Nauk. SSSR Seriya. Biol. 4, 485-497 (1982).

44. Mayasnikov, V. \& Stepanova, S. in Orbital Station MIR 300-305 (Institute of Biomedical Problems: State Scientific Center of Russian Federation, 2008).

45. Iwasaki, K. I. et al. Long-duration spaceflight alters estimated intracranial pressure and cerebral blood velocity. J. Physiol. 599, 1067-1081 (2021).

46. Arbeille, P., Achaibou, F., Fomina, G., Pottier, J. M. \& Porcher, M. Regional blood flow in microgravity: adaptation and deconditioning. Med. Sci. Sports Exerc. 28, S70-S79 (1996).

47. Arbeille, P. et al. Adaptation of the left heart, cerebral and femoral arteries, and jugular and femoral veins during short- and long-term head-down tilt and spaceflights. Eur. J. Appl. Physiol. 86, 157-168 (2001).

48. Pourcelot, L. et al. in Life Sciences Research in Space: Proceedings of the Second European Symposium (ESA SP-212) 119-123 (ESA Scientific and Technical Publications, 1984).

49. Arbeille, P., Fomina, G., Achaibou, F., Pottier, J. \& Kotovskaya, A. Cardiac and vascular adaptation to $0 \mathrm{~g}$ with and without thigh cuffs (Antares 14 and Altair 21 day Mir spaceflights). Acta Astronaut 36, 753-762 (1995).

50. Bagian, J. P. \& Hackett, P. Cerebral blood flow: comparison of ground-based and spaceflight data and correlation with space adaptation syndrome. J. Clin. Pharm. 31, 1036-1040 (1991).

51. Zuj, K. A. et al. Impaired cerebrovascular autoregulation and reduced $\mathrm{CO}(2)$ reactivity after long duration spaceflight. Am. J. Physiol. Heart Circ. Physiol. 302, H2592-H2598 (2012).

52. Blaber, A. P., Goswami, N., Bondar, R. L. \& Kassam, M. S. Impairment of cerebral blood flow regulation in astronauts with orthostatic intolerance after flight. Stroke 42, 1844-1850 (2011).

53. Bishop, C. C., Powell, S., Rutt, D. \& Browse, N. L. Transcranial Doppler measurement of middle cerebral artery blood flow velocity: a validation study. Stroke 17, 913-915 (1986)

54. Brauer, P. et al. Correlation of transcranial Doppler sonography mean flow velocity with cerebral blood flow in patients with intracranial pathology. $J$. Neurosurg. Anesthesiol. 10, 80-85 (1998).

55. Du Boulay, G. H. \& Symon, L. The anaesthetist's effect upon the cerebral arteries. Proc. R. Soc. Med. 64, 77-80 (1971).

56. Coverdale, N. S., Gati, J. S., Opalevych, O., Perrotta, A. \& Shoemaker, J. K. Cerebra blood flow velocity underestimates cerebral blood flow during modest hypercapnia and hypocapnia. J. Appl Physiol. 117, 1090-1096 (2014).

57. Arbeille, P. et al. Lower body negative pressure reduces jugular and portal vein volumes and counteracts the elevation of middle cerebral vein velocity during long-duration spaceflight. J. Appl Physiol. 131, 1080-1087 (2021).

58. Bateman, G. A. \& Bateman, A. R. Spaceflight-associated increase in middle cerebral vein velocity: collapse, collateral flow, or hyperemia? J. Appl Physiol. 131, 1392-1393 (2021).

59. $\mathrm{Si}, \mathrm{Z}$. et al. MRI-based investigation on outflow segment of cerebral venous system under increased ICP condition. Eur. J. Med. Res. 13, 121-126 (2008).

60. Nicogossian, A. E., Huntoon, E. L. \& Pool, S. L. (Lea and Febiger, USA, 1989)

61. Taylor, C. R. et al. Spaceflight-induced alterations in cerebral artery vasoconstrictor, mechanical, and structural properties: implications for elevated cerebral perfusion and intracranial pressure. FASEB J. 27, 2282-2292 (2013).
62. Roberts, D. R. et al. Altered cerebral perfusion in response to chronic mild hypercapnia and head-down tilt Bed rest as an analog for Spaceflight. Neuroradiology https://doi.org/10.1007/s00234-021-02660-8 (2021).

63. Najarian, T. et al. Prolonged hypercapnia-evoked cerebral hyperemia via $\mathrm{K}(+)$ channel- and prostaglandin E(2)-dependent endothelial nitric oxide synthase induction. Circ. Res. 87, 1149-1156 (2000).

64. Cannizzaro, G., Garbin, L., Clivati, A. \& Pesce, L. I. Correction of hypoxia and hypercapnia in COPD patients: effects on cerebrovascular flow. Monaldi Arch. Chest Dis. 52, 9-12 (1997).

65. Pollock, J. M. et al. Hypercapnia-induced cerebral hyperperfusion: an underrecognized clinical entity. AJNR Am. J. Neuroradiol. 30, 378-385 (2009).

66. Prisk, G. K., Fine, J. M., Cooper, T. K. \& West, J. B. Vital capacity, respiratory muscle strength, and pulmonary gas exchange during long-duration exposure to microgravity. J. Appl Physiol. 101, 439-447 (2006).

67. Vavilala, M. S., Lee, L. A. \& Lam, A. M. Cerebral blood flow and vascular physiology. Anesthesiol. Clin. North Am. 20, 247-264 (2002).

68. Tschoe, $C$. et al. Changes in mean arterial pressure and end-tidal carbon dioxide content affect venous sinus pressures in patients with idiopathic intracranial hypertension: a randomized study. J. Neurointerv. Surg. 12, 906-910 (2020).

69. Bateman, A. R., Bateman, G. A. \& Barber, T. The relationship between cerebral blood flow and venous sinus pressure: can hyperemia induce idiopathic intracranial hypertension? Fluids Barriers CNS 18, 5 (2021).

70. Bateman, G. A., Lechner-Scott, J. \& Lea, R. A. A comparison between the pathophysiology of multiple sclerosis and normal pressure hydrocephalus: is pulse wave encephalopathy a component of MS? Fluids Barriers CNS 13, 18 (2016).

\section{AUTHOR CONTRIBUTIONS}

Conceptualisation and design: G.A.B. and A.R.B. Mathematical analysis: A.R.B. Writing original draft: G.A.B. Review and editing: all authors. All authors read and approved the final paper.

\section{COMPETING INTERESTS}

The authors declare no competing interests.

\section{ADDITIONAL INFORMATION}

Supplementary information The online version contains supplementary material available at https://doi.org/10.1038/s41526-022-00188-6.

Correspondence and requests for materials should be addressed to Grant Alexander Bateman.

Reprints and permission information is available at http://www.nature.com/ reprints

Publisher's note Springer Nature remains neutral with regard to jurisdictional claims in published maps and institutional affiliations.

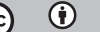

Open Access This article is licensed under a Creative Commons Attribution 4.0 International License, which permits use, sharing, adaptation, distribution and reproduction in any medium or format, as long as you give appropriate credit to the original author(s) and the source, provide a link to the Creative Commons license, and indicate if changes were made. The images or other third party material in this article are included in the article's Creative Commons license, unless indicated otherwise in a credit line to the material. If material is not included in the article's Creative Commons license and your intended use is not permitted by statutory regulation or exceeds the permitted use, you will need to obtain permission directly from the copyright holder. To view a copy of this license, visit http://creativecommons. org/licenses/by/4.0/.

(c) Crown 2022 